\title{
Insulin resistance and abnormal albumin excretion in non-diabetic first-degree relatives of patients with NIDDM
}

\author{
C.M. Forsblom ${ }^{1}$, J. G. Eriksson ${ }^{2}$, A. V. Ekstrand ${ }^{1}$, A.-M. Teppo ${ }^{1}$, M.-R. Taskinen ${ }^{2}$, L. C. Groop ${ }^{3}$ \\ ${ }^{1}$ Fourth Department of Medicine, Helsinki University Hospital, Helsinki, Finland \\ ${ }^{2}$ Third Department of Medicine, Helsinki University Hospital, Helsinki, Finland \\ ${ }^{3}$ Department of Endocrinology, University of Lund, Malmö General Hospital, Malmö, Sweden
}

\begin{abstract}
Summary Microalbuminuria has recently been associated with insulin resistance in both insulin-dependent and non-insulin-dependent (NIDDM) diabetes mellitus. To establish whether microalbuminuria in non-diabetic subjects as well is associated with insulin resistance and associated abnormalities in glucose and lipid metabolism, oral glucose tolerance tests were performed with measurement of urinary albumin excretion rate, lipids and lipoproteins in 582 male non-diabetic first-degree relatives of patients with NIDDM. In addition, insulin sensitivity was assessed in 20 of these subjects with the euglycaemic hyperinsulinaemic clamp technique. Abnormal albumin excretion rate (AER), defined as AER 15$200 \mu \mathrm{g} / \mathrm{min}$, was associated with higher systolic blood pressure $(p<0.05)$, higher fasting glucose values $(p<0.05)$, lower HDL-cholesterol $(p<0.05)$ and lower apolipoprotein A-I $(p<0.05)$ concentrations than
\end{abstract}

observed in subjects with normal AER. The rate of glucose metabolism was lower in subjects with abnormal compared to subjects with normal albumin excretion rate $(38.0 \pm 2.8$ vs $47.3 \pm 2.4 \mu \mathrm{mol} \cdot \mathrm{kg}$ lean body mass $\left.^{-1} \cdot \min ^{-1} ; p=0.028\right)$. This difference was almost completely accounted for by a reduction in non-oxidative glucose metabolism $(17.7 \pm 1.9$ vs $27.4 \pm 2.7 \mu \mathrm{mol} \cdot \mathrm{kg}$ lean body $\operatorname{mass}^{-1} \cdot \mathrm{min}^{-1} ; \quad p=$ $0.010)$, which correlated inversely with the AER $(r=-0.543 ; p=0.013)$. These results suggest that in non-diabetic individuals genetically predisposed to NIDDM, abnormal AER is associated with insulin resistance and abnormalities in glucose and lipid metabolism. [Diabetologia (1995) 38: 363 -369]

Key words Microalbuminuria, insulin resistance syndrome, insulin sensitivity, euglycaemic hyperinsulinaemic clamp.
Microalbuminuria (urinary albumin excretion rate $20-200 \mu \mathrm{g} / \mathrm{min}$ ) is a strong independent predictor of cardiovascular morbidity and mortality in diabetic and non-diabetic subjects [1-8]. Although the link between microalbuminuria and cardiovascular disease is unknown, insulin resistance has emerged as a common denominator [9-13]. In patients with both insu-

Received: 19 April 1994 and in revised form: 20 September 1994

Corresponding author: Dr. L. C. Groop, Department of Endocrinology, University of Lund, Malmö General Hospital, S21401 Malmö, Sweden

Abbreviations: LBM, lean body mass; IDDM, Insulin-dependent diabetes mellitus, HDL, high-density lipoprotein; NIDDM, non-insulin-dependent diabetes mellitus; VLDL, very low density lipoprotein; AER, albumin excretion rate; OGTT, oral glucose tolerance test. lin-dependent (IDDM) and non-insulin-dependent diabetes mellitus (NIDDM) microalbuminuria is associated with insulin resistance, hyperinsulinaemia, hypertriglyceridaemia, low HDL-cholesterol concentrations and hypertension, which all are considered features of the insulin resistance syndrome [9-13]. Since hyperglycaemia can increase albumin excretion rate (AER) in subjects without diabetic nephropathy [14] and induce insulin resistance [15], it is not known from studies in patients with IDDM or NIDDM whether insulin resistance and increased AER are due to differences in glycaemic control. To test the hypothesis that an increased AER is associated with insulin resistance and abnormalities of glucose and lipid metabolism we compared estimates of insulin sensitivity, glucose tolerance, insulin, lipid and lipoprotein concentrations between non-diabetic 
subjects with increased ( $>15 \mu \mathrm{g} / \mathrm{min})$ and normal AER.

\section{Subjects and methods}

The Botnia Study was initiated in 1990 in western Finland, and aimed at identifying genetic and early metabolic defects in persons at increased risk of developing NIDDM. As part of this study we have measured urinary AER in 582 male first-degree relatives of patients with NIDDM. Informed consent was obtained from all subjects, and the study protocol was approved by the local ethic committees. The subjects participated in a 75-g oral glucose tolerance test (OGTT) performed after a 12 $\mathrm{h}$ overnight fast. Venous blood samples were taken at $-5,0,30$, 60 and $120 \mathrm{~min}$ for determination of plasma glucose and serum insulin concentrations. Area under the glucose and insulin curves were calculated for the glucose tolerance test. Urine was collected during the OGTT (mean $\pm \mathrm{SD}$; urine volume $170 \pm 112 \mathrm{ml}$ ) and the AER was determined from timed $(154 \pm 24 \mathrm{~min})$ urine samples. Abnormal AER was defined as $15-200 \mu \mathrm{g} / \mathrm{min}$. In a subset of subjects $(n=87)$ overnight timed urine samples were collected. The AER measured during the short urine sampling correlated strongly with the AER measured during overnight urine collection $(r=0.59 ; p<0.001)$. Six subjects (two with newly diagnosed NIDDM, two with impaired and two with normal glucose tolerance) with manifest albuminuria (AER $>200 \mu \mathrm{g} / \mathrm{min}$ ) were excluded from the study to avoid inclusion of subjects with kidney disease of nondiabetic origin. Three blood pressure recordings with 5-min intervals were obtained from the right arm of a sitting person, and the mean value was calculated. The first measurement was performed after $10 \mathrm{~min}$ of rest. Waist circumference was measured on standing subjects with a soft tape at the midaxillary line, midway between the lowest rib margin and the iliac crest. Hip circumference was measured over the widest part of the gluteal region [16]. Lean body mass (LBM) was determined using near-infrared spectroscopy with measurement of the layer of the biceps region of the dominant arm using Futrex 5000 equipment (Futrex Inc., Gaithersburg, MD, USA) [17]. The equipment automatically calculates the fat percentage and fatfree mass from an equation which is based on hydrostatically determined body fat. LDL-cholesterol was calculated using the Friedewald formula [18].Insulin sensitivity was assessed in ten subjects with abnormal AER (33.2 \pm 3.8 ; range 18.5 to $51.6 \mu \mathrm{g} / \mathrm{min})$ and in ten subjects with normal AER (6.3 \pm 0.6 ; range 4.2 to $9.0 \mathrm{\mu g} / \mathrm{min}$ ) with a euglycaemic hyperinsulinaemic clamp [19]. The AER in these subjects was based on the mean value of the AER in three overnight urine collections. These two groups were matched for age $(53.8 \pm 3.9$ vs $50.5 \pm$ 3.3 years $)$, body mass index $\left(25.9 \pm 1.0 \mathrm{vs} 26.6 \pm 0.6 \mathrm{~kg} \cdot \mathrm{m}^{-2}\right)$, waist to hip ratio $(0.99 \pm 0.02$ vs $0.98 \pm 0.01)$, systolic $(136 \pm 7$ vs $135 \pm 4 \mathrm{~mm} \mathrm{Hg}$ ) and diastolic $(81 \pm 4$ vs $84 \pm 2 \mathrm{~mm} \mathrm{Hg}$ ) blood pressure. The groups were also identical for a family history of hypertension and prevalence of smokers. Furthermore, physical activity, as estimated from a questionnaire assessing the amount and intensity of daily working and leisure time exercise was identical in the two groups. After three baseline samples had been obtained for measurement of glucose and insulin concentrations, a primed constant infusion of short-acting human insulin (Actrapid; Novo Nordisk Industri, Copenhagen, Denmark) was administered at a rate of $45 \mathrm{mU} / \mathrm{min} \cdot \mathrm{m}^{2}$ body surface area for $150 \mathrm{~min}$. The plasma glucose concentration was determined at 5 -min intervals, and an infusion of $20 \% \mathrm{glu}-$ cose was adjusted to maintain a constant plasma glucose concentration. Indirect calorimetry was used for $\mathbf{3 0 ~} \mathrm{min}$ in the ba- sal state and during the last $30 \mathrm{~min}$ of the clamp to estimate net rates of substrate oxidation [20]. A computerized, open-circuit system was used to measure gas exchange (Deltatrac; Datex, Helsinki, Finland). Non-oxidative glucose metabolism, which mainly $(>90 \%$ ) reflects glycogen synthesis in skeletal muscle [21], was calculated as the difference between total body glucose uptake and glucose oxidation as determined by indirect calorimetry. The constants to calculate glucose, lipid and protein oxidation from gas exchange data are given in the review by Ferrannini [20]. In previous studies, hepatic glucose production as measured with the tritiated glucose technique was almost totally suppressed in non-diabetic first-degree relatives of NIDDM patients under similar experimental conditions [22]. Therefore, hepatic glucose production was considered to be completely suppressed during the insulin clamp in both groups in our study. All results are expressed relative to the LBM.

\section{Analytical methods}

Blood glucose during the oral glucose tolerance test was measured by a hexokinase method (Boehringer Mannheim, Mannheim, Germany). Plasma glucose during the euglycaemic clamp was assayed with a glucose oxidase method using a Beckman Glucose Analayzer II (Beckman, Fullerton, Calif., USA). Serum insulin concentration was determined by a double-antibody radioimmunoassay (Pharmacia, Uppsala, Sweden). The sensitivity of the method is $15 \mathrm{pmol} / \mathrm{l}$, and the interassay coefficient of variation was $5 \%$. Serum total cholesterol, HDL-cholesterol and triglycerides were measured by commercially available kits with Cobas Mira analyzer (HoffmannLA Roche, Basel, Switzerland). Apolipoprotein A-I, A-II and $B$ concentrations in plasma were determined by immunoturbidimetric methods (Boehringer GmbH, No 726478 and 726 486; Boehringer Mannheim; Orion Diagnostica, Espoo, Finland). The interassay variations for apolipoprotein A-I, AII and B were 3.6, 2.1 and $4.9 \%$, respectively. Urine albumin concentration was determined immunoturbidimetrically [23]. The detection limit for the assay was $5 \mathrm{mg} / \mathrm{l}$ and the interassay coefficient of variance was $7.5 \pm 1 \%$. Urine urea concentration was measured with a commercially available kit using an enzymatic method (Labsystems, Helsinki, Finland).

\section{Statistical analysis}

All data are expressed as mean \pm SEM unless otherwise stated. The significance of the difference between group means was tested with the Mann-Whitney test using a BMDP statistical package (Biomedical Data Processing 1988, Los Angeles, Calif., USA). Correlations were tested by linear regression analysis after $\log _{e}$ transformation of AER. A p-value less than 0.05 was considered statistically significant.

\section{Results}

Based upon World Health Organization criteria, 30 $(5.2 \%)$ relatives had previously unknown diabetes and $134(23.0 \%)$ had impaired glucose tolerance. Prevalence of abnormal AER was slightly, although not significantly higher in subjects with NIDDM $(10.0 \%)$ and impaired glucose tolerance $(11.2 \%)$ 
Table 1. Mean (SD) characteristics of subjects with normal and abnormal albumin excretion rate

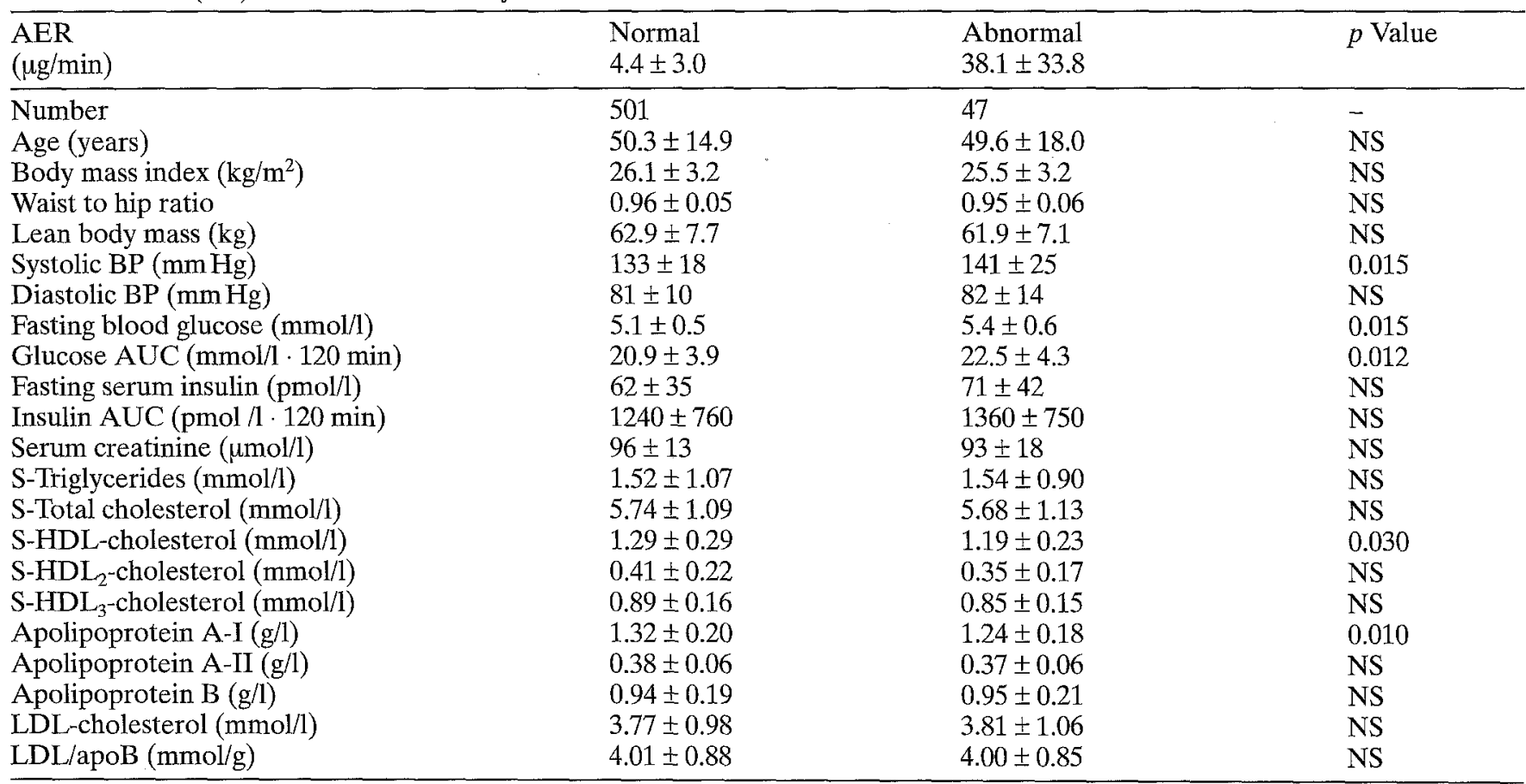

AER, Albumin excretion rate; AUC, area under curve; LDL/apoB, the ratio between LDL-cholesterol and apolipoprotein B concentrations; NS, non-significant $p$-value $>0.05$

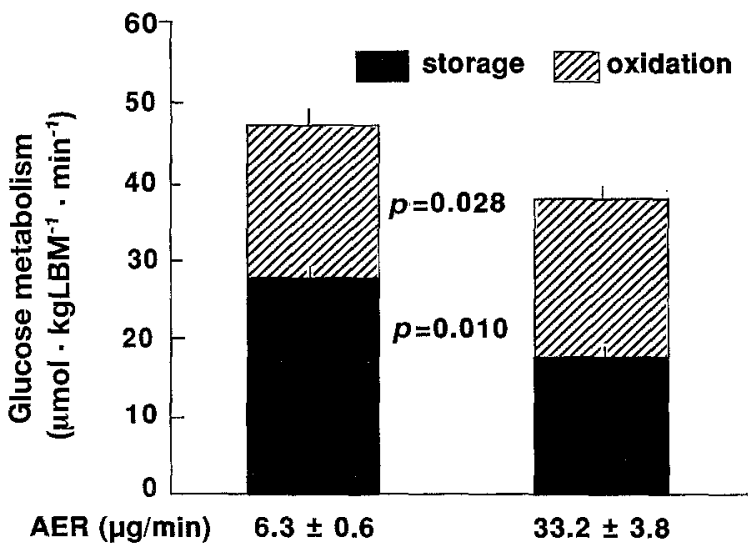

Fig. 1. Glucose metabolism in subjects by albumin excretion rate. Rate of total glucose metabolism $(p=0.028)$ and glucose storage $(p=0.010)$ was reduced in subjects with abnormal vs subjects with normal AER

than in those with normal glucose tolerance $(7.7 \%)$. Non-diabetic subjects with abnormal AER had higher systolic blood pressure $(p<0.05)$, higher blood glucose $(p<0.05)$, lower HDL-cholesterol $(p<0.05)$ and lower apolipoprotein A-I $(p<0.05)$ concentrations than normoalbuminuric subjects (Table 1). Albumin excretion rate correlated positively but weakly with systolic blood pressure $(r=0.101$; $p=0.018)$ and $120-$ min serum insulin concentrations $(r=0.110 ; p=0.010)$. The rate of total glucose disposal was lower in subjects with abnormal compared with subjects with normal AER $(38.0 \pm 2.8$ vs

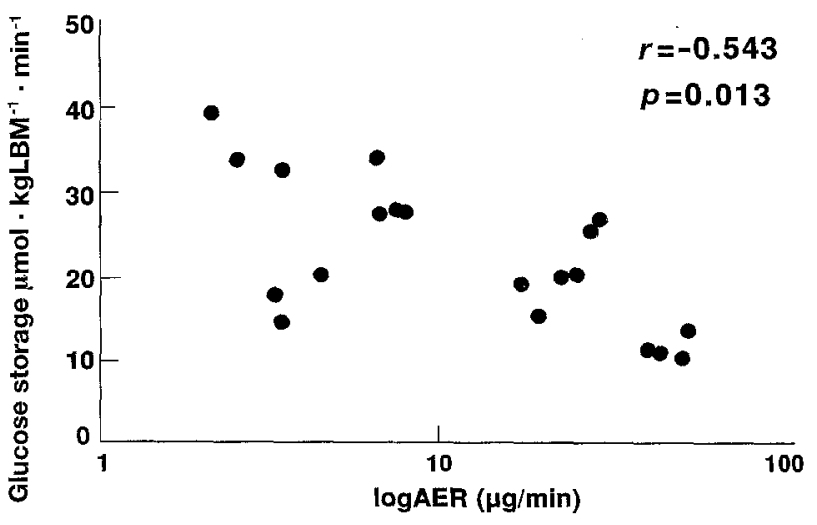

Fig. 2. Relationship between albumin excretion rate and glucose storage $(r=-0.543, p=0.013)$

$\left.47.3 \pm 2.4 \mu \mathrm{mol} \cdot \mathrm{kgLBM}^{-1} \cdot \mathrm{min}^{-1} ; p=0.028\right)$, primarily due to a reduction in non-oxidative glucose metabolism $\left(17.7 \pm 1.9\right.$ vs $27.4 \pm 2.7 \mu \mathrm{mol} \cdot \mathrm{kgLBM}^{-1}$. $\left.\min ^{-1} ; p=0.010\right)$ (Fig.1), since the rates of glucose oxidation did not significantly differ between the two groups $\left(10.5 \pm 1.1\right.$ and $8.5 \pm 1.0 \mu \mathrm{mol} \cdot \mathrm{kgLBM}^{-1}$. $\left.\min ^{-1} ; p=\mathrm{NS}\right)$. The rate of non-oxidative glucose metabolism correlated inversely with the AER ( $r=$ $-0.543 ; p=0.013$ )(Fig. 2). Basal rates of lipid oxidation were similar in patients with abnormal and nor$\mathrm{mal}$ AER $(1.24 \pm 0.11$ and $1.33 \pm 0.11 \mu \mathrm{mol}$. $\left.\mathrm{kgLBM}^{-1} \cdot \mathrm{min}^{-1} ; \quad p=\mathrm{NS}\right)$ and suppressed to the same degree during the hyperinsulinaemic clamp $\left(0.69 \pm 0.10\right.$ and $0.61 \pm 0.15 \mu \mathrm{mol} \cdot \mathrm{kgLBM}^{-1} \cdot \mathrm{min}^{-1}$; $p=\mathrm{NS})$. Similarly, basal rates of protein oxidation 
did not differ between the two groups $(5.73 \pm 0.81$ and $\left.\quad 6.20 \pm 0.77 \mu \mathrm{mol} \cdot \mathrm{kgLBM}^{-1} \cdot \min ^{-1} ; \quad p=\mathrm{NS}\right)$. Therefore, rates of energy expenditure in the basal state $\left(81.7 \pm 3.3\right.$ and $81.8 \pm 2.6 \mathrm{~J} \cdot \mathrm{kgLBM}^{-1} \cdot \mathrm{min}^{-1}$; $p=\mathrm{NS})$ and during the clamp $(87.0 \pm 3.4$ and $86.0 \pm 3.0 \mathrm{~J} \cdot \mathrm{kgLBM}^{-1} \cdot \mathrm{min}^{-1} ; p=\mathrm{NS}$ ) were similar in subjects with abnormal and normal AER.

\section{Discussion}

Microalbuminuria is associated with insulin resistance both in patients with NIDDM [11] and IDDM [12-13]. However, in patients with manifest diabetes, insulin resistance can develop as a consequence of chronic hyperglycaemia and the degree of albumin excretion can vary with the degree of glycaemia $[14$, 15]. In these patients it may therefore be difficult to draw conclusions on pathogenetic links between insulin resistance and microalbuminuria. Insulin resistance is also a common feature of non-diabetic firstdegree relatives of patients with NIDDM and it is generally thought that this insulin resistance is of genetic origin $[22,24,25]$. This study provides the first evidence that even among these non-diabetic highrisk individuals, insulin resistance is associated with microalbuminuria. The study also demonstrates that this insulin resistance almost exclusively affects the action of insulin on non-oxidative glucose metabolism, i. e. glycogen synthesis in skeletal muscle [21]. Impaired activation by insulin of the key enzyme of this pathway, glycogen synthase, is a consistent finding in insulin-resistant offspring of patients with NIDDM $[24,26]$. Further support for the view that this defect may be genetic in origin comes from a study demonstrating impaired action of insulin on glycogen synthase in cultured fibroblasts from patients with NIDDM [27]. Although we did not measure glycogen synthase activity in muscle in this study it can be speculated that an inherited defect in glycogen metabolism also contributes to insulin resistance in the microalbuminuric patients of this study. The finding of an association between XbaI polymorphism of the glycogen synthase gene and NIDDM, particularly insulin-resistant NIDDM with hypertension, raises interesting possibilities for a genetic control of insulin resistance [28]. Hypertension is also associated with insulin resistance [29] and in this, and other studies [30, 31], individuals with abnormal AER had higher blood pressure than those with normal AER. Haffner et al. [32] showed that insulin resistance, indicated by elevated fasting insulin concentrations, precedes the development of diabetes and hypertension in a non-diabetic population. Similarly, insulin resistance was also found to predict the development of hypertension and microalbuminuria in NIDDM patients [10]. If the same is true for non-diabetic subjects, insulin resistance in sub- jects with microalbuminuria could be partially ascribed to the presence of hypertension. However, the microalbuminuric and normoalbuminuric subjects participating in the clamp study were matched for blood pressure levels, suggesting that microalbuminuria in the absence of hypertension could also be associated with insulin resistance. This does not exclude the possibility that they may have had elevated blood pressure during the night which could only have been detected by $24-\mathrm{h}$ blood pressure monitoring. If the subjects with abnormal AER had demonstrated the fullblown insulin resistance syndrome they also should have presented with abdominal obesity and characteristic lipid disturbances, i.e. high triglyceride and low HDL-cholesterol concentrations. No increase in waist-hip ratio was observed in subjects with abnormal AER and the observed differences in metabolic parameters were unrelated to body mass index (BMI). Nevertheless, subjects with abnormal AER had lower HDL-cholesterol concentrations and lower apolipoprotein A-I concentrations, compared with subjects with normal AER. Interestingly, despite this reduction in HDL-cholesterol, the triglyceride concentrations were similar in the two groups. In general, changes in HDL-cholesterol and triglyceride concentrations in response to metabolic alterations or drugs are opposed but concomitant, appearing together as a couple [33,34]. There are several potential explanations for the disassociation of HDL and triglyceride responses. First, triglyceride concentrations show larger variability both within and between individuals than HDL-cholesterol concentrations [35]. Therefore, it is easier to detect changes in HDL-cholesterol than in triglyceride concentrations. Although both triglyceride and HDL-cholesterol concentrations are independently related to insulin resistance $[36,37]$, recent studies by Blonk et al. [38] suggest a direct role of insulin in the regulating of triglyceride levels but not of HDLconcentrations. Importantly, this effect was thought to be independent of insulin sensitivity. Note that the two groups of the present study did not differ with respect to BMI, waist/hip ratio and fasting insulin, all known to influence triglyceride levels [39]. Several studies have demonstrated that subjects with low HDL but normal triglyceride levels have a high apo A-I fractional catabolic rate [40-42]. Recently, Horowitz et al. [43] suggested that apo A-I is more loosely bound to HDL and therefore dissociates more readily. Leroy et al. [44] demonstrated that HDL particles, containing only apo A-I (LpA-I), with diameters of $8.8 \mathrm{~nm}$ are the least stable particles. Since small LpA-I particles reside between $\mathrm{HDL}_{2}$ and $\mathrm{HDL}_{3}$ densities the loss of these particles could explain the decrease of $\mathrm{HDL}_{2}$ and $\mathrm{HDL}_{3}$-cholesterol concentrations. Free apo A-I is cleared by kidneys and this could be accentuated by an abnormal AER. Blades et al. [45] have reported that a high hepatic li- 
pase activity is associated with low HDL but normal VLDL levels. In addition, there is evidence to suggest that insulin resistance may influence the activity of both lipoprotein and hepatic lipase enzymes [46, 47]. In support of this, we have observed a decrease in lipoprotein lipase/hepatic lipase ratio in insulin-resistant males [48]. In subjects with abnormal AER, the changes in lipolytic enzymes could destabilize HDL particles and promote dissociation of apo A-I resulting in a more rapid clearance of apo A-I.

Earlier reports in non-diabetic populations [30, 49] have shown that microalbuminuric subjects have higher triglyceride concentrations than subjects with normal AER. In these reports there was a more marked difference in insulin concentrations between the normo- and microalbuminuric groups than in the current study, suggesting that the microalbuminuric patients were more insulin resistant. Furthermore, the subjects in the paper by Mykkänen et al. [49] were 20 years older and had a higher prevalence of hypertension and obesity than the subjects in our study. In consequence, the prevalence of microalbuminuria in their non-diabetic subjects was also much higher $(32 \%)$ than the prevalence found in our study population $(9 \%)$.

The reported prevalence of microalbuminuria in non-diabetic subjects has varied between $6.3 \%$ and $13.3 \%[7,30,31,50]$. In our study we used an AER measured from a timed urine sample collected during an OGTT. The same approach has been used in other population studies [7]. In addition to being easy to perform, the circumstances are well standardised and reliable. All subjects are sitting during the OGTT and drinking the same amount of fluid. Values of AER obtained in this way also correlated significantly with AER in overnight urine collections in this study. The logarithm of AER during the OGTT represents a continuum, not a bimodal distribution. Changing the cut-off level for definition of abnormal AER (15ug/min) does not change the results nor the message of the study.

What could explain the association between microalbuminuria and insulin resistance? Two possible sequences of events should be considered. First, in IDDM, microalbuminuria reflects microvascular damage [51]. The disturbance in microcirculation could lead to changes in muscular blood flow and flux through the capillary endothelium. This, in turn, could change muscle fiber type from oxidative type 1 fibers to glycolytic type $2 \mathrm{~b}$ fibers, the latter being associated with insulin resistance [52]. On the other hand, insulin resistance is generally accompanied by hyperinsulinaemia and subjects with abnormal AER had higher fasting insulin concentrations. In non-diabetic men, an acute increase in serum insulin concentrations increases the transcapillary escape rate of albumin [53]. Insulin also stimulates the sympathetic nervous system [54] and the increase in catechol- amines could influence the intraglomerular pressure by affecting the blood flow to the glomeruli. Although direct experimental proof for either of these two scenarios is lacking, the data demonstrate an association between insulin resistance and its related abnormalities on one side and microalbuminuria as a sign of vascular damage on the other. This could provide an explanation for the association between insulin resistance and cardiovascular disease [55]. Microalbuminuria could help to identify those insulin-resistant individuals who already present with early signs of vascular dysfunction.

Acknowledgements. We thank Ms. M. Gullström and the Botnia research team for skilled technical assistance. This study was supported by grants from the Sigrid Jusélius Foundation, the Nordisk Insulin Foundation, the Finnish Diabetes Research Foundation, the Perklén Foundation, and Finska Läkaresällskapet.

\section{References}

1. Jensen T, Borch-Johnsen K, Kofoed-Enevoldsen A, Deckert T (1987) Coronary heart disease in young type 1 (insulin-dependent) diabetic patients with and without diabetic nephropathy: incidence and risk factors. Diabetologia 30:144-148

2. Jarrett RJ, Viberti GC, Argyropoulos A, Hill RD, Mahmud U, Murrells TJ (1984) Microalbuminuria predicts mortality in non-insulin dependent diabetes mellitus. Diabet Med 1:17-19

3. Schmitz A, Vaeth M (1988) Microalbuminuria: a major risk factor in non-insulin-dependent diabetes. A 10-year followup study of 503 patients. Diabet Med 5:126-134

4. Mattock MB, Keen H, Viberti GC et al. (1988) Coronary heart disease and urinary albumin excretion rate in Type 2 (non-insulin dependent) diabetic patients. Diabetologia 31:82-87

5. Mattock MB, Morrish NJ, Viberti GC, Keen H, Fitzgerald AP, Jackson G (1992) Prospective study of microalbuminuria as predictor of mortality in NIDDM. Diabetes $41: 736-741$

6. Damsgaard EM, Fröland A, Jörgensen OD, Mogensen CE (1990) Microalbuminuria as predictor of increased mortality in elderly people. BMJ 300:297-300

7. Yudkin JS, Forrest RD, Jackson CA (1988) Microalbuminuria as predictor of vascular disease in non-diabetic subjects. Lancet II:530-533

8. Jarrett RJ (1984) The epidemiology of coronary heart disease and related factors in the context of diabetes mellitus and impaired glucose tolerance. In: Jarrett R (ed) Diabetes and heart disease. Elsevier, Amsterdam, pp 1-23

9. Groop L, Ekstrand A, Forsblom C et al. (1993) Insulin resistance, hypertension and microalbuminuria in patients with type 2 (non-insulin-dependent) diabetes mellitus. Diabetologia 36:642-647

10. Nosadini R, Solini A, Velussi M et al. (1994) Impaired insulin-induced glucose uptake by extrahepatic tissue is hallmark of NIDDM patients who have or will develop hypertension and microalbuminuria. Diabetes 43:491-499

11. Niskanen L, Laakso M (1993) Insulin resistance is related to albuminuria in patients with type 2 (non-insulin dependent) diabetes mellitus. Metabolism 42:1541-1545 
12. Yip J, Mattock MB, Morocutti A, Sethi M, Trevisan R, Viberti GC (1993) Insulin resistance in insulin-dependent diabetic patients with microalbuminuria. Lancet 342:883887

13. Barnett AH, Bain SC (1993) Microalbuminuria and insulin resistance in diabetes mellitus [commentary]. Lancet 342:880-881

14. Groop L, Mäkipernaa A, Stenman S, DeFronzo RA, Teppo AM (1990) Urinary excretion of kappa light chains in patients with diabetes mellitus. Kidney Int 37:1120-1125

15. Yki-Järvinen H (1992) Glucose toxicity. Endocr Rev $13: 415-431$

16. World Health Organization (1987) Measuring obesity classification and description of anthropometric data. Report on a WHO Consultation on the Epidemiology of Obesity. Warsaw: WHO, Geneva, pp 2-7

17. Franssila-Kallunki A (1992) Comparison of near-infrared light spectroscopy, bioelectrical impedance and tritiated water techniques for the measurement of fat-free mass in humans. Scand J Clin Lab Invest 52:879-885

18. Friedewald WT, Levy RI, Fredrickson DS (1972) Estimation of the concentration of low-density lipoprotein cholesterol in plasma, without use of the preparative ultracentrifuge. Clin Chem 18:499-502

19. DeFronzo RA, Tobin JD, Andres R (1979) Glucose clamp technique: a method for quantifying insulin secretion and resistance. Am J Physiol 237:E214-E223

20. Ferrannini $E$ (1988) The theoretical bases of indirect calorimetry: a review. Metabolism 37:287-301

21. Shulman GI, Rothman DL, Jue T, Stein P, DeFronzo RA, Shulman RG (1990) Quantitation of muscle glycogen synthesis in normal subjects and subjects with non-insulindependent diabetes by ${ }^{13} \mathrm{C}$ nuclear magnetic resonance spectroscopy. N Engl J Med 322:223-228

22. Eriksson J, Franssila-Kallunki A, Ekstrand A et al. (1989) Early metabolic defects in persons at increased risk for non-insulin-dependent diabetes mellitus. N Engl J Med 321:337-343

23. Teppo AM (1982) Immunoturbidimetry of albumin and immunoglobulin $\mathrm{G}$ in urine. Clin Chem 28:1359-1361

24. Vaag A, Henriksen JE, Beck-Nielsen H (1992) Decreased insulin activation of glycogen synthase in skeletal muscles in young nonobese Caucasian first-degree relatives of patients with non-insulin-dependent diabetes mellitus. J Clin Invest 89:782-788

25. Gulli G, Ferrannini E, Stern M, Haffner S, DeFronzo RA (1992) The metabolic profile of NIDDM is fully established in glucose-tolerant offspring of two Mexican-American NIDDM parents. Diabetes 41:1575-1586

26. Schalin-Jäntti C, Härkönen M, Groop L (1992) Impaired activation of glycogen synthase in people at increased risk for developing NIDDM. Diabetes 41:598-604

27. Wells AM, Sutcliffe IC, Johnson AB, Taylor R (1993) Abnormal activation of glycogen synthesis in fibroblasts from NIDDM subjects. Evidence for an abnormality specific to glucose metabolism. Diabetes 42:583-589

28. Groop LC, Kankuri M, Schalin-Jäntti C et al. (1993) Association between polymorphism of the glycogen synthase gene and non-insulin-dependent diabetes mellitus. N Engl J Med 328:10-14

29. Ferrannini E, Buzzigoli G, Bonadonna R et al. (1987) Insulin resistance in essential hypertension. $\mathrm{N}$ Engl $\mathrm{J}$ Med 317:350-357

30. Haffner SM, Stern MP, Kozlowski Gruber MK, Hazuda HP, Mitchell BD, Patterson JK (1990) Microalbuminuria. Potential marker for increased cardiovascular risk factors in nondiabetic subjects? Arteriosclerosis 10:727-731
31. Gould MM, Mohamed-Ali V, Goubet SA, Yudkin JS, Haines AP (1993) Microalbuminuria: associations with height and sex in non-diabetic subjects. BMJ 306:240242

32. Haffner SM, Valdez RA, Hazuda HP, Mitchell BD, Morales PA, Stern MP (1992) Prospective analysis of the insulin-resistance syndrome (syndrome $\mathrm{X}$ ). Diabetes 41:715722

33. Davis CE, Gordon D, LaRosa J, Wood PDS, Halperin M (1980) Correlations of plasma high density lipoprotein cholesterol levels with other plasma lipid and lipoprotein concentrations. Circulation 62[Suppl.IV]:IV24-IV30

34. Silverman DI, Ginsburg GS, Pasternak RC (1993) Highdensity lipoprotein subfractions. Am J Med 94:636-645

35. Austin MA (1991) Plasma triglyceride and coronary heart disease. Arterioscler Thromb 11:2-14

36. Abbott WGH, Lillioja S, Young AA et al. (1987) Relationships between plasma lipoprotein concentrations and insulin action in an obese hyperinsulinemic population. Diabetes 36:897-904

37. Garg A, Helderman JH, Koffler M, Ayuso R, Rosenstock J, Raskin P (1988) Relationship between lipoprotein levels and in vivo insulin action in normal young white men. Metabolism 37:982-987

38. Blonk MC, Jacobs MAJM, Friedberg CE et al. (1994) Determinants of insulin sensitivity and consequences for lipoproteins and blood pressure in subjects with non-insulindependent diabetes mellitus. Metabolism 43:501-508

39. Després JP, Moorjani S, Lupien PJ, Tremblay A, Nadeau A, Bouchard C (1990) Regional distribution of body fat, plasma lipoproteins, and cardiovascular disease. Arterioscler 10:497-511

40. Brinton EA, Eisenberg S, Breslow JL (1991) Increased apo A-I and apo A-II fractional catabolic rate in patients with low high density lipoprotein-cholesterol levels with or without hypertriglyceridemia. J Clin Invest 87:536-544

41. Gylling H, Vega GL, Grundy SM (1992) Physiologic mechanisms for reduced apolipoprotein A-I concentrations associated with low levels of high density lipoprotein cholesterol in patients with normal plasma lipids. J Lipid Res 33:1527-1539

42. Ginsberg HN, Ngai C, Wang XI, Ramakrishnan R (1993) Increased production rates of LDL are common in inviduals with low plasma levels of HDL cholesterol, independent of plasma triglyceride concentrations. Arterioscler Thromb 13:842-851

43. Horowitz BS, Goldberg IJ, Merab J, Vanni TM, Ramakrishnan R (1993) Increased plasma and renal clearance of an exchangeable pool of apolipoprotein A-I in subjects with low levels of high density lipoprotein cholesterol. J Clin Invest $91: 1743-1752$

44. Leroy A, Harms Toohill KL, Fruchart JC, Jonas A (1993) Structural properties of high density lipoprotein subclasses homogenous in protein composition and size. J Biol Chem 268:4798-4805

45. Blades B, Vega GL, Grundy SM (1993) Activities of lipoprotein lipase and hepatic triglyceride lipase in postheparin plasma of patients with low concentrations of HDL cholesterol. Arterioscler Thromb 13:1227-1235

46. Baynes C, Henderson AD, Anyaoku V et al. (1991) The role of insulin insensitivity and hepatic lipase in the dyslipidaemia of type 2 diabetes. Diabet Med 8:560-566

47. Godsland IF, Crook D, Walton C, Wynn V, Oliver MF (1992) Influence of insulin resistance, secretion, and clearance on serum cholesterol, triglycerides, lipoprotein cholesterol, and blood pressure in healthy men. Arterioscler Thromb 12:1030-1035 
48. Knudsen P, Eriksson J, Lahdenperä S et al. (1995) Changes of lipolytic enzymes cluster with insulin resistance syndrome. Diabetologia 38: 344-350

49. Mykkänen L, Haffner SM, Kuusisto J, Pyörälä K, Laakso M (1994) Microalbuminuria precedes the development of NIDDM. Diabetes 43:552-557

50. Winocour PH, Harland JOE, Millar JP, Laker MF, Alberti KGMM (1992) Microalbuminuria and associated cardiovascular risk factors in the community. Atherosclerosis 93:71-81

51. Deckert T, Feldt-Rasmussen B, Borch-Johnsen K, Jensen T, Kofoed-Enevoldsen A (1989) Albuminuria reflects widespread vascular damage. The Steno hypothesis. Diabetologia 32:219-226
52. Lillioja S, Young AA, Culter CL et al. (1987) Skeletal muscle capillary density and fiber type are possible determinants of in vivo insulin resistance in man. J Clin Invest $80: 415-424$

53. Nestler JE, Barlascini CO, Tetrault GA, Fratkin MJ, Clore JN, Blackard WG (1990) Increased transcapillary escape rate of albumin in nondiabetic men in response to hyperinsulinemia. Diabetes 39:1212-1217

54. Rowe JW, Young JB, Minaker KL, Stevens AL, Pallotta J, Landsberg L (1981) Effect of insulin and glucose infusions on sympathetic nervous system activity in normal man. Diabetes 30:219-225

55. Reaven GM (1988) Role of insulin resistance in human disease. Diabetes 37:1595-1607 